\title{
Coordination-driven self-assembly vs dynamic covalent chemistry: versatile methods for the synthesis of molecular metallarectangles
}

\author{
Li-Li Ma ${ }^{\ddagger 1}$, Jia-Qin Han ${ }^{\ddagger 1,2}$, Wei-Guo Jia ${ }^{* 2}$ and Ying-Feng Han*1
}

\section{Full Research Paper}

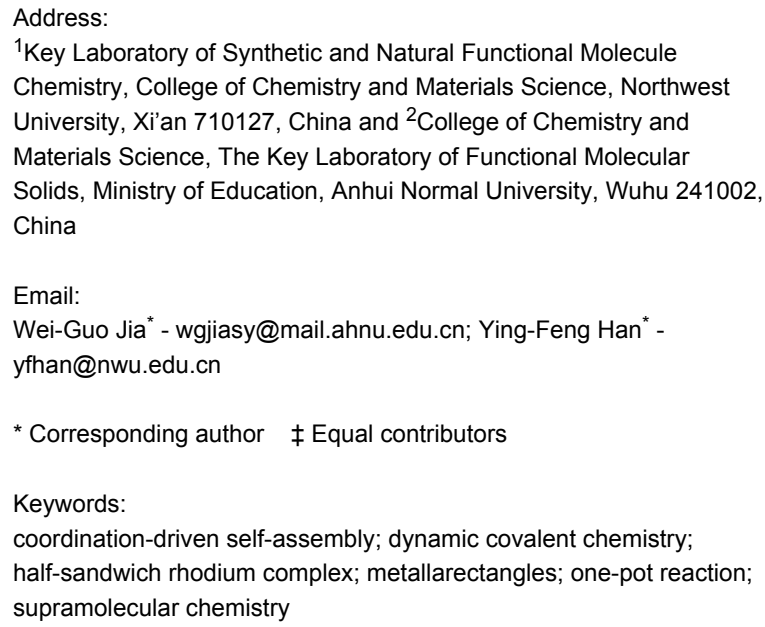

${ }^{1}$ Key Laboratory of Synthetic and Natural Functional Molecule Chemistry, College of Chemistry and Materials Science, Northwest University, Xi'an 710127, China and ${ }^{2}$ College of Chemistry and Materials Science, The Key Laboratory of Functional Molecular Solids, Ministry of Education, Anhui Normal University, Wuhu 241002, China

Email:

Wei-Guo Jia* - wgjiasy@mail.ahnu.edu.cn; Ying-Feng Han ${ }^{*}$ -

yfhan@nwu.edu.cn

* Corresponding author $\ddagger$ Equal contributors

Keywords:

coordination-driven self-assembly; dynamic covalent chemistry;

half-sandwich rhodium complex; metallarectangles; one-pot reaction; supramolecular chemistry

Beilstein J. Org. Chem. 2018, 14, 2027-2034.

doi:10.3762/bjoc. 14.178

Received: 01 June 2018

Accepted: 19 July 2018

Published: 03 August 2018

This article is part of the thematic issue "Macrocyclic and supramolecular chemistry".

Guest Editor: M.-X. Wang

(c) 2018 Ma et al.; licensee Beilstein-Institut. License and terms: see end of document.

\begin{abstract}
Supramolecular coordination assemblies have a range of potential applications in chemical and biological sciences. Herein, simple modular methods for the synthesis of metallarectangles are described. The desired tetranuclear metallarectangles were synthesized by using coordination-driven self-assembly of half-sandwich rhodium-based organometallic clip units and organic ligands. The reaction of such an organometallic clip with 4-formylpyridine provided a dinuclear molecular tweezer with pendant aldehyde groups, and subsequent $[4+4]$ condensation reactions with diamines provides another route to the target metallarectangles in good yields. The same assemblies can also be easily isolated in one-pot procedures by mixing the organometallic clip, diamines and 4-formylpyridine.
\end{abstract}

\section{Introduction}

Over the past two decades, supramolecular structures with organometallic half-sandwich fragments have attracted much attention, including metallarectangles, metallacages and Borromean-type rings. Moreover, many of these structures have been utilized for various applications, such as catalysts, host-guest chemistry and others [1-17]. Through the use of a range of diverse functional ligands, the coordination-driven self-assembly has been proven to be a powerful tool to construct supramolecular architectures with controlled shapes and sizes [18-30]. Using this strategy, a host of exciting supramolecular 
structures have been constructed by using two elaborately designed building blocks, such as dinuclear half-sandwich molecular clips and appropriate pyridyl ligands. The sizes and structures of the obtained molecular rectangles, cages or rings can be easily tuned by adjusting the length and shape of the bridging ligands and molecular clips. We and others have reported a suite of $[2+2]$ tetranuclear metallarectangles, each formed using dinuclear molecular clips and pyridyl-based donor ligands [6-9,31-36]. The introduction of dynamic covalent bonds (such as imine $\mathrm{C}=\mathrm{N}$ bonds), could allow the multicomponent assembly of such architectures using rather simple precursors, however, studies along these lines are rare [37]. Thus, the preparation of single and discrete supramolecular architectures via dynamic covalent bond-driven self-assembly remains challenging. Severin and co-workers have recently shown that metallamacrocycles and cages based on half-sandwich ruthenium could be obtained in one-pot reactions from simple building blocks $[38,39]$. This finding prompted us to investigate whether condensation reactions between amines and 4-formylpyridine can be used simultaneously with coordination bond formation to construct metallarectangle structures in one-pot reactions, thereby reducing both waste and the number of reaction steps.

In this work we successfully combine coordination-driven selfassembly and dynamic covalent chemistry through imine bond formation between amines and 4-formylpyridine to construct the desired rectangular tetrarhodium molecular rectangles.

\section{Results and Discussion}

The different approaches to the synthesis of tetranuclear molecular rectangles used in this work are shown in Scheme 1. We and others have used a two-step supramolecular design strategy for the formation of half-sandwich metal-based metallarectangles and metallacages [6-9]. Following this approach, two self-assembled metallarectangles with different bridging linkers 3a,b were synthesized by utilizing the $\left[\mathrm{Cp}^{*}{ }_{2} \mathrm{Rh}_{2}\left(\mu-\eta^{2}-\eta^{2}-\right.\right.$ $\left.\mathrm{C}_{2} \mathrm{O}_{4}\right) \mathrm{Cl}_{2}$ ] unit as molecular clips (Scheme 1, method A).

Precursor complex 1, which bears two labile triflato ligands was prepared in situ by chloride abstraction from $\left[\mathrm{Cp}^{*}{ }_{2} \mathrm{Rh}_{2}\left(\mu-\eta^{2}-\eta^{2}-\right.\right.$ $\left.\mathrm{C}_{2} \mathrm{O}_{4}\right) \mathrm{Cl}_{2}$ ] with AgOTf. Stirring a mixture of $\mathbf{1}$ and $\mathbf{L 1}$ in a 1:1 molar ratio in methanol for $24 \mathrm{~h}$ resulted in a homogeneous, dark-red solution. The ${ }^{1} \mathrm{H}$ NMR spectrum of the obtained solution displays significant downfield shifts of the pyridyl signals, consistent with the loss of electron density upon coordination of the nitrogen atom to the metal centers (Figure 1a,b). Analysis of the reaction solution using electrospray ionization mass spectrometry (ESIMS) showed a signal at $m / z=476.1010$, corresponding to a tertracation species of complex 3a. The peak was isotopically resolved and agrees well with the theoretical isotopic distribution. In addition, the IR spectrum of the rhodium metallarectangle 3a showed a $\mathrm{C}=\mathrm{N}$ stretching band at $1618 \mathrm{~cm}^{-1}$.

The same self-assembly protocol can also be used for the synthesis of metallarectangle $\mathbf{3 b}$. The combination of two labileligand precursor complexes $\mathbf{1}$ and two pyridyl-based ligands $\mathbf{L 2}$ in a 1:1 molar ratio led to the formation of $\mathbf{3 b}$ in good yield. The ${ }^{1} \mathrm{H}$ NMR spectrum of the reaction mixture revealed the formation of a single species. In the ${ }^{1} \mathrm{H}$ NMR spectrum of $\mathbf{3 b}$, only one sharp set of characteristic peaks was found. Again, significant downfield shifts of the pyridyl proton signals were observed, indicating the efficient self-assembly of the rhodiumbased assembly (Figure 2a,b). Clear evidence for the formation of a discrete tetranuclear organometallic product was obtained from ESI mass spectrometry. Similar to that observed in complex 3a, a peak at $m / z=450.0868$ was observed, which is attributable to $[3 \mathbf{b}-4 \mathrm{OTf}]^{4+}$, and its isotopic pattern is in good agreement with the theoretical distribution (Figure 3, right). The absorption band at $1620 \mathrm{~cm}^{-1}$ in the IR spectrum indicated the existence of an imine group.

The geometries of the metallarectangles $\mathbf{3 a}$ and $\mathbf{3 b}$ were expected to be similar, as they comprise two oxalate-bridged halfsandwich rhodium fragments linked by two Schiff-base ligands $\mathbf{L 1}$ or L2, giving the desired tetranuclear metallarectangles. In order to test the possibility of using dynamic covalent chemistry to assemble these metallarectangles, we attempted a further method (Scheme 1, method B) to synthesize these assemblies. As shown in Scheme 1, a dinuclear molecular tweezer complex 2 bearing two pendant aldehyde groups can be formed from the labile ligand complex 1 and 4-formylpyridine, and subsequent reaction with diamines would potentially give tetranuclear metallarectangles. When equimolar amounts of either trans4,4'-stilbenediamine or 1,5-diaminonaphthalene were added to methanol solutions of complex 2 , and allowed to react for $24 \mathrm{~h}$ at room temperature, the formation of tetranuclear $[4+4]$ condensation products 3a (Figure 1c) and 3b (Figure 2c) was observed, respectively. Complexes $\mathbf{3 a}$ and $\mathbf{3 b}$ were isolated in good yields, and their structures were confirmed by ${ }^{1} \mathrm{H}$ NMR spectroscopy and ESI mass spectrometry.

After establishing that the condensation reaction of $\mathbf{2}$ with amines is an efficient method to form metallarectangles, we sought to test the possibility of forming the desired assemblies in a one-pot reaction, i.e., the combination of coordinationdriven and dynamic covalent self-assembly strategies (Scheme 1, method C) [33]. When a mixture of the labile ligand complex 1, trans-4,4'-stilbenediamine and 4-formylpyridine in a 1:1:1 molar ratio in methanol was allowed to react for $24 \mathrm{~h}$ at room temperature, the clear, quantitative formation of complex 3a was revealed by NMR spectrometry (Figure 1e). The analo- 


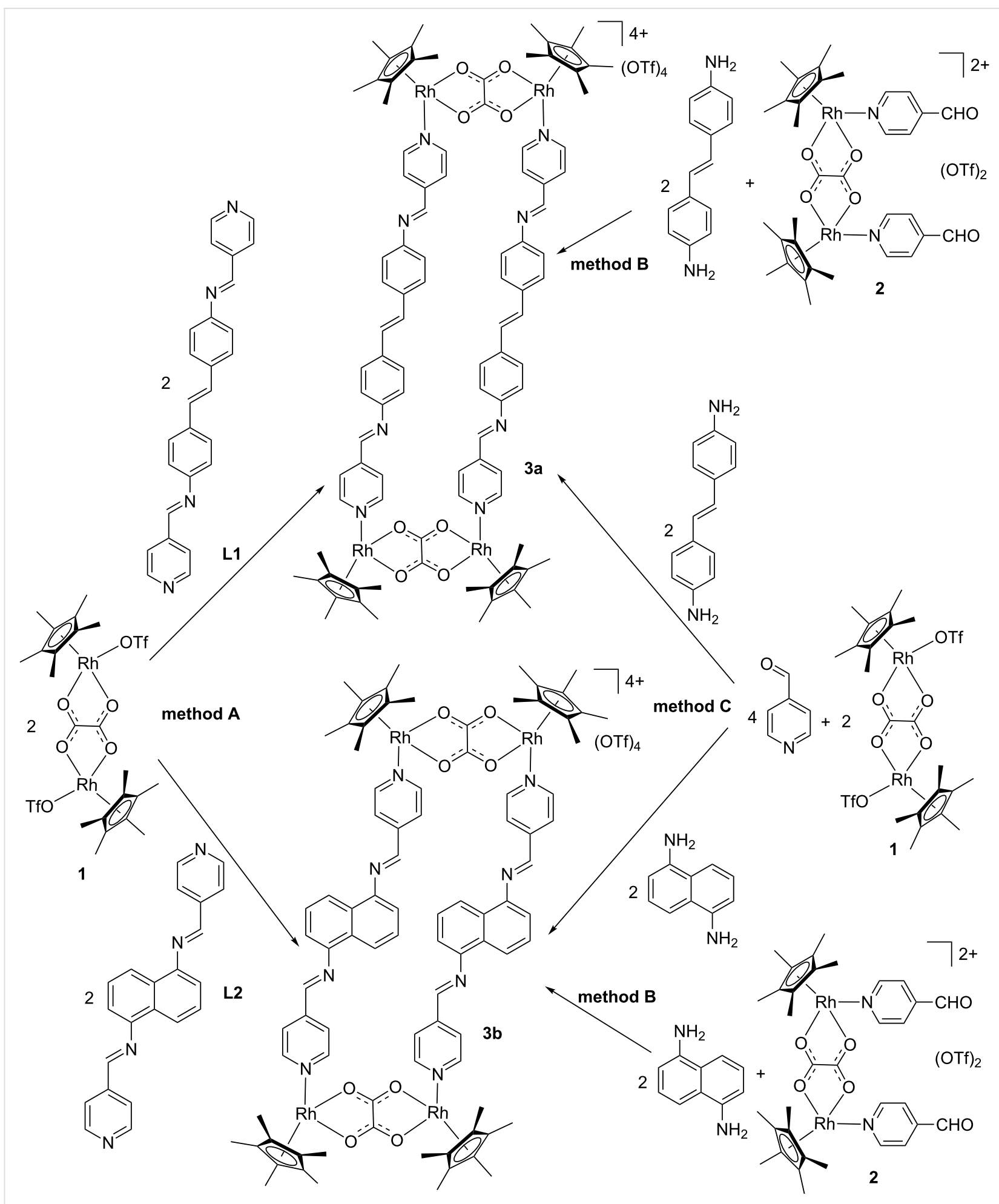

Scheme 1: Synthesis of half-sandwich rhodium metallarectangles via three different methods. Method A: coordination-driven self-assembly of organometallic clips and organic ligands; method B: [4 + 4] condensation reactions of half-sandwich rhodium-based dialdehyde complexes with diamines; method C: assembly of metallarectangles with organometallic clip, diamines and 4-formylpyridine in a one-pot procedure.

gous one-pot construction of $\mathbf{3 b}$ was also successful (Figure 2e). Notably, the isolated yields of the metallarectangles are higher than the overall yields of the two-step method.
Since attempts to obtain X-ray quality single crystals of the target metallarectangles were unsuccessful, molecular simulations were performed to gain further insight into the 
(e)

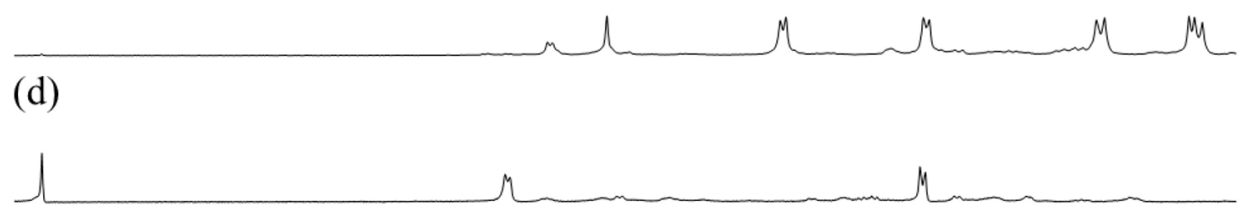

(c)

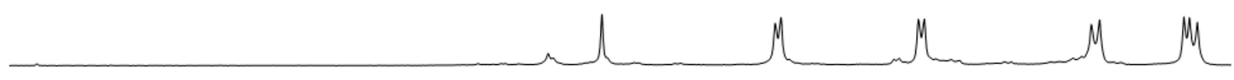

(b)

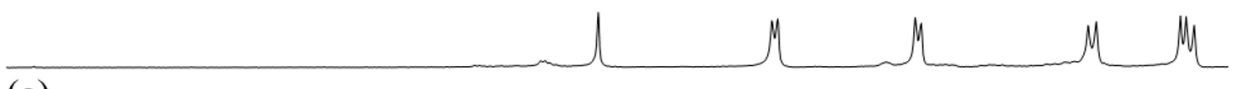

(a)

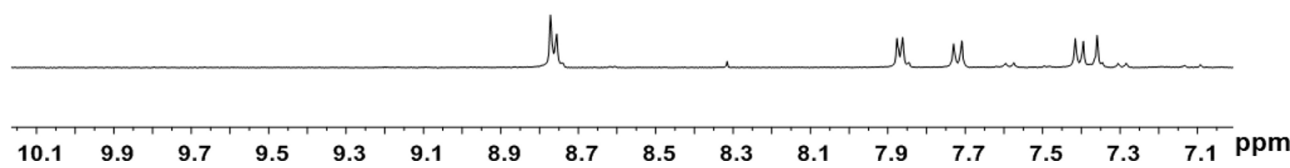

Figure 1: Partial ${ }^{1} \mathrm{H}$ NMR spectra $\left(400 \mathrm{MHz}\right.$, DMSO- $d_{6}, \mathrm{ppm}$ ) of (a) L1; (b) the sample of metallarectagle 3 a obtained by coordination-driven selfassembly of organometallic clip 1 and L1 (method A); (c) the sample of metallarectagle 3a obtained through [4 +4$]$ condensation reactions of halfsandwich rhodium-based dialdehyde complex 2 with trans-4,4'-stilbenediamine (method B); (d) half-sandwich rhodium-based dialdehyde 2; (e) the product of self-assembly of organometallic clip 1, trans-4,4'-stilbenediamine and 4-formylpyridine in a one-pot procedure (method C).

(e)

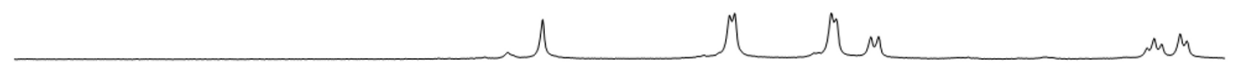

(d)

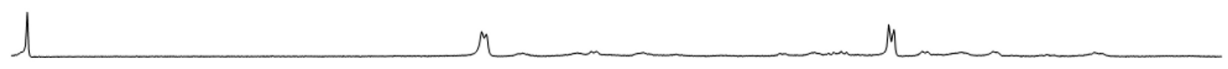

(c)

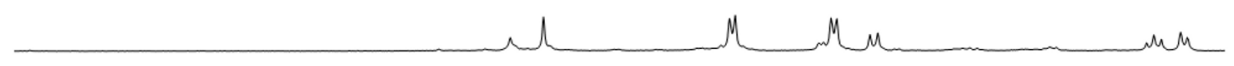

(b)

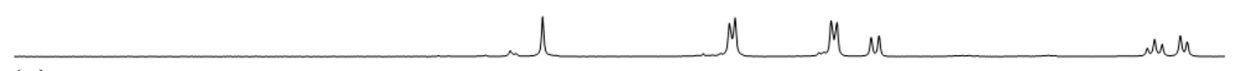

(a)

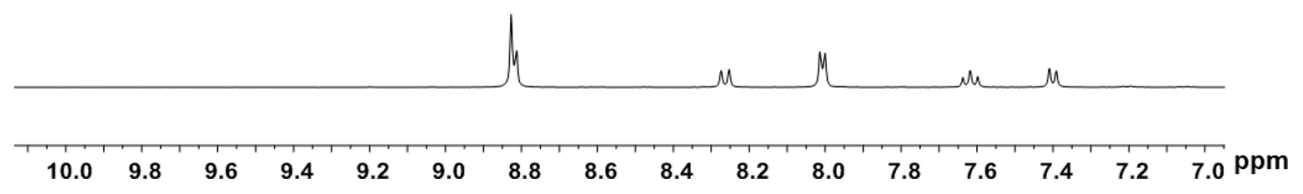

Figure 2: Partial ${ }^{1} \mathrm{H}$ NMR spectra $\left(400 \mathrm{MHz}\right.$, DMSO- $d_{6}$, ppm) of (a) L2; (b) a sample of metallarectangle 3 b obtained by coordination-driven selfassembly of organometallic clip 1 and L2 (method A); (c) a sample of metallarectangle 3 b obtained by [4+4] condensation reactions of half-sandwich rhodium-based dialdehyde complex 2 with 1,5-diaminonaphthalene (method B); (d) half-sandwich rhodium-based dialdehyde 2; (e) the product of assembly of organometallic clip 1, 1,5-diaminonaphthalene and 4-formylpyridine in a one-pot procedure $(\operatorname{method~C)}$.

structures of the assemblies $\mathbf{3} \mathbf{a}$ and $\mathbf{3 b}$. The optimized structures of each assembly featured a similar rectangular metallacyclic macrocycle structure (Figure 4). The sizes of the assembled structures were estimated to be $26.3 \times 5.6 \AA(\mathbf{3 a})$ and $20.1 \times 5.6 \AA(\mathbf{3 b})$.

\section{Conclusion}

In summary, a modular protocol for the synthesis of metallarectangles is described. The desired tetranuclear metallarectangles can be obtained via three different approaches: 1) exploiting the coordination-driven self-assembly of half- 


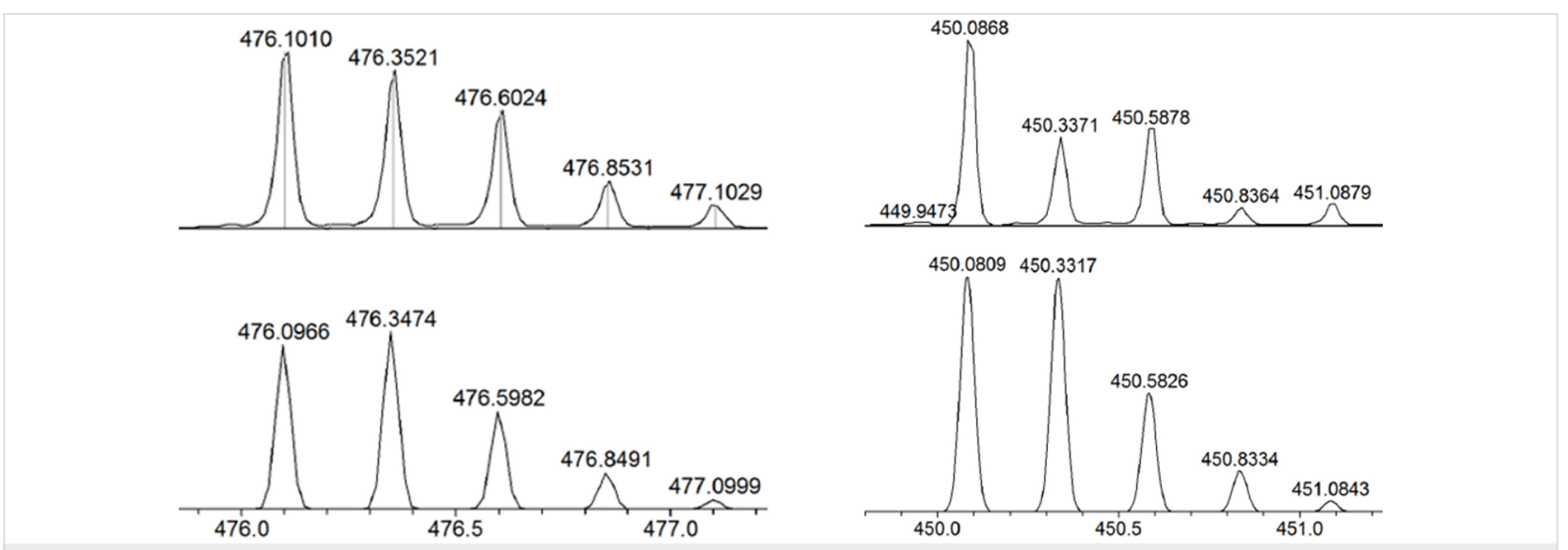

Figure 3: Calculated (bottom) and experimental (top) ESI-MS spectra of the tetracationic half-sandwich rhodium metallarectangles [3a - $40 \mathrm{OTf}]^{4+}$ (left) and $[3 \mathrm{~b}-4 \mathrm{OTf}]^{4+}$ (right).
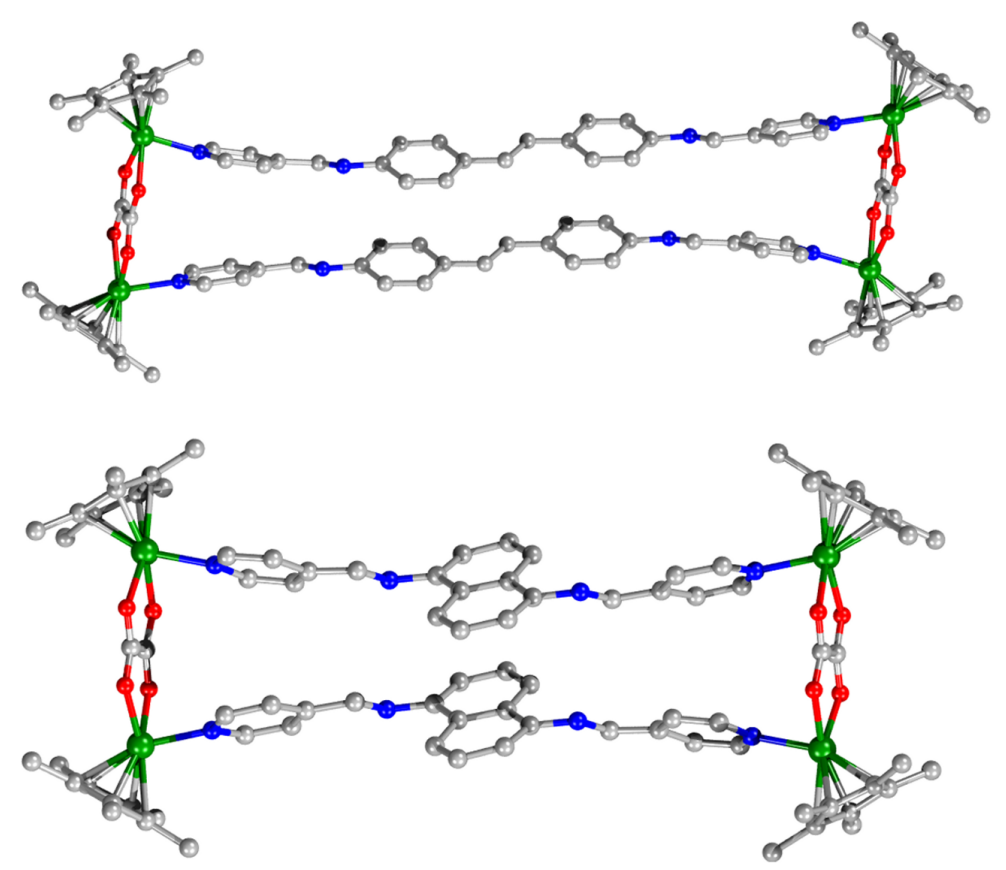

Figure 4: Optimized structures of the charged metallarectangles $\mathbf{3 a}$ (top) and $\mathbf{3 b}$ (bottom), optimized with the molecular mechanics force field. The graphics were produced using the Diamond software package. Colors: $\mathrm{C}$, gray; O, red; N, blue; rhodium, green (hydrogen atoms have been removed for clarity)

sandwich rhodium-based organometallic clips and organic ligands, 2) $[4+4]$ condensation reactions of diamines with dinuclear molecular tweezer complex bearing pendant aldehyde groups, and 3) a sample one-pot procedure involving mixing the organometallic clips, diamines and 4-formylpyridine. Our results thus present versatile and efficient approaches to the synthesis of molecular metallarectangles with intricate topologies. The methods shown here are potentially useful for the synthesis of functional molecular metallacages, and the experimental efforts in this direction are currently underway.

\section{Experimental \\ Materials and methods}

All manipulations were performed under an atmosphere of nitrogen using standard Schlenk techniques. Commercial grade solvents and reagents were used without further purification. $\left[\mathrm{Cp}^{*}{ }_{2} \mathrm{Rh}_{2}\left(\mu-\eta^{2}-\eta^{2}-\mathrm{C}_{2} \mathrm{O}_{4}\right) \mathrm{Cl}_{2}\right.$ ] [25], trans-4,4'-stilbenediamine [40] and $\mathbf{L 2}$ [41] were prepared according to literature procedures. Methanol was purified by standard methods prior to use. NMR (400 MHz) spectra were obtained on a Bruker AVANCE III spectrometer. IR spectra of the solid samples ( $\mathrm{KBr}$ tablets) 
were recorded on a Bruker EQUINOX-55 (TENSOR27) IR spectrometer. Mass spectra were obtained with UltiMate 3000 spectrometers.

\section{General procedure for the synthesis of $\mathbf{L 1}$ and L2}

L1: To 4-formylpyridine (195 mg, $1.82 \mathrm{mmol}$ ) in dry $\mathrm{CH}_{3} \mathrm{OH}$ $(20 \mathrm{~mL})$ was added trans-4,4'-stilbenediamine $(191 \mathrm{mg}$, $0.91 \mathrm{mmol}$ ) at room temperature. The mixture was stirred at room temperature for $24 \mathrm{~h}$ and then filtered. The resulting yellow solid was washed with methanol $(2 \times 5 \mathrm{~mL})$ and diethyl ether $(2 \times 5 \mathrm{~mL})$ to give L1 $(318 \mathrm{mg}, 90 \%) .{ }^{1} \mathrm{H}$ NMR (400 MHz, DMSO- $\left.d_{6}, \mathrm{ppm}\right) \delta 8.77$ (s, 2H, -NCH-), 8.76 (d, $J=$ $6.0 \mathrm{~Hz}, 4 \mathrm{H}), 7.87$ (d, $J=6.0 \mathrm{~Hz}, 4 \mathrm{H}), 7.72(\mathrm{~d}, J=8.4 \mathrm{~Hz}, 4 \mathrm{H})$, $7.41(\mathrm{~d}, J=8.4 \mathrm{~Hz}, 4 \mathrm{H}), 7.36(\mathrm{~s}, 2 \mathrm{H},-\mathrm{CH}=\mathrm{CH}-)$; IR (KBr, cm $\left.{ }^{-1}\right)$ : $3419(\mathrm{~m}), 1597$ (s), 1411 (m), 962 (m), 831 (s), $632(\mathrm{~m}), 561(\mathrm{~s})$.

L2: A modified synthetic procedure adapted from literature methods [33] was used. To 4-formylpyridine $(215 \mathrm{mg}$, $2.0 \mathrm{mmol})$ in dry $\mathrm{CH}_{3} \mathrm{OH}(20 \mathrm{~mL})$ was added 1,5-diaminonaphthalene $(160 \mathrm{mg}, 1.0 \mathrm{mmol})$ at room temperature. The mixture was stirred at room temperature for $24 \mathrm{~h}$ and then filtered. The resulting yellow solid was washed with diethyl ether $(2 \times 3 \mathrm{~mL})$ and crystallized from $\mathrm{CH}_{2} \mathrm{Cl}_{2}$ /hexane (1:1) to give $\mathbf{L 2}$ (220 mg, $65 \%$ ). ${ }^{1} \mathrm{H}$ NMR (400 MHz, DMSO- $\left.d_{6}, \mathrm{ppm}\right) \delta 8.83$ (s, $2 \mathrm{H}$, -NCH-), 8.82 (d, $J=6.0 \mathrm{~Hz}, 4 \mathrm{H}), 8.26$ (d, $J=8.4 \mathrm{~Hz}, 2 \mathrm{H}), 8.01$ $(\mathrm{d}, J=6.0 \mathrm{~Hz}, 4 \mathrm{H}), 7.62(\mathrm{t}, 2 \mathrm{H}), 7.40$ (d, $J=7.2 \mathrm{~Hz}, 2 \mathrm{H})$; IR $\left(\mathrm{KBr}, \mathrm{cm}^{-1}\right)$ : 3024 (w), 1624 (s), 1597 (s), 1404 (s), 1317 (s), 1232 (s), 925 (s), 790 (s), 652 (m).

\section{Synthesis of complex 2 $\left[\mathrm{Cp}_{2}{ }_{2} \mathrm{Rh}_{2}\left(\mu-\eta^{2}-\eta^{2}-\mathrm{C}_{2} \mathrm{O}_{4}\right)(4-\mathrm{CHOPy})_{2}\right](\mathrm{OTf})_{2}$} AgOTf (36 mg, $0.14 \mathrm{mmol}$ ) was added to a solution of $\left[\mathrm{Cp}_{2}{ }_{2} \mathrm{Rh}_{2}\left(\mu-\eta^{2}-\eta^{2}-\mathrm{C}_{2} \mathrm{O}_{4}\right) \mathrm{Cl}_{2}\right](45 \mathrm{mg}, 0.07 \mathrm{mmol})$ in $\mathrm{CH}_{3} \mathrm{OH}$ $(15 \mathrm{~mL})$ at room temperature and the mixture was stirred for $1 \mathrm{~h}$, followed by filtration to remove insoluble materials. Then 4-formylpyridine ( $16 \mathrm{mg}, 0.14 \mathrm{mmol}$ ) was added to the filtrate and the mixture was stirred for $24 \mathrm{~h}$. The volume was reduced to $3 \mathrm{~mL}$ in vacuo. Upon the addition of diethyl ether, a lightyellow solid was precipitated and washed with diethyl ether $(3 \times 3 \mathrm{~mL})$ and dried under vacuum $(60 \mathrm{mg}, 80 \%) .{ }^{1} \mathrm{H} \mathrm{NMR}$ (400 MHz, DMSO- $\left.d_{6}, \mathrm{ppm}\right) \delta 10.09$ (s, 2H, -CHO), 8.89 (d, $J=$ $5.0 \mathrm{~Hz}, 4 \mathrm{H}), 7.82(\mathrm{~d}, J=5.0 \mathrm{~Hz}, 4 \mathrm{H}), 1.55(\mathrm{~s}, 30 \mathrm{H}$, $\left.\mathrm{Cp}^{*}-\mathrm{H}\right)$; HRMS-ESI $(\mathrm{m} / \mathrm{z})$ : $[2-2 \mathrm{OTf}]^{2+}$ calcd for $\mathrm{C}_{34} \mathrm{H}_{40} \mathrm{O}_{12} \mathrm{~N}_{2} \mathrm{~F}_{6} \mathrm{~S}_{2} \mathrm{Rh}_{2}$, 390.0571; found, 390.0541 .

\section{Synthesis of $\left[\mathrm{Cp}^{*}{ }_{4} \mathrm{Rh}_{4}\left(\mu-\eta^{2}-\eta^{2}-\right.\right.$ $\left.\left.\mathrm{C}_{2} \mathrm{O}_{4}\right)_{2}(\mathrm{~L} 1)_{2}\right](\mathrm{OTf})_{4}(\mathbf{3 a})$}

Method A: AgOTf (36 mg, $0.14 \mathrm{mmol}$ ) was added to a solution of $\left[\mathrm{Cp}^{*}{ }_{2} \mathrm{Rh}_{2}\left(\mu-\eta^{2}-\eta^{2}-\mathrm{C}_{2} \mathrm{O}_{4}\right) \mathrm{Cl}_{2}\right](45 \mathrm{mg}, 0.07 \mathrm{mmol})$ in
$\mathrm{CH}_{3} \mathrm{OH}(30 \mathrm{~mL})$ at room temperature and the mixture was stirred for $1 \mathrm{~h}$, followed by filtration to remove insoluble materials. Then a solution of $\mathbf{L} 1(27 \mathrm{mg}, 0.07 \mathrm{mmol})$ in $15 \mathrm{~mL}$ $\mathrm{CHCl}_{3}$ was added dropwise to the filtrate. The mixture was stirred at room temperature for $24 \mathrm{~h}$ to give a deep red solution. The volume was reduced to $3 \mathrm{~mL}$ in vacuo. Upon the addition of diethyl ether, a black-red solid was precipitated and washed with $\mathrm{CHCl}_{3}(2 \times 3 \mathrm{~mL})$ and dried under vacuum (61 mg, 70\%). ${ }^{1} \mathrm{H}$ NMR (400 MHz, DMSO- $\left.d_{6}, \mathrm{ppm}\right) \delta 8.64$ (s, 4H, -NCH-), 8.18 (d, $J=6.0 \mathrm{~Hz}, 8 \mathrm{H}), 7.81$ (d, $J=6.4 \mathrm{~Hz}$, $8 \mathrm{H}), 7.36(\mathrm{~d}, J=8.8 \mathrm{~Hz}, 8 \mathrm{H}), 7.12(\mathrm{~d}, J=6.0 \mathrm{~Hz}, 8 \mathrm{H}), 7.09$ $(\mathrm{s}, 4 \mathrm{H}), 1.57(\mathrm{~s}, 60 \mathrm{H}, \mathrm{Cp} *-\mathrm{H})$. HRMS-ESI $(\mathrm{m} / \mathrm{z})$ : [3a-4OTf $]^{4+}$ calcd for $\mathrm{C}_{100} \mathrm{H}_{100} \mathrm{O}_{20} \mathrm{~N}_{8} \mathrm{~F}_{12} \mathrm{~S}_{4} \mathrm{Rh}_{4}, 476.0966$; found, 476.0986 .

Method B: trans-4,4'-Stilbenediamine (14 mg, $0.07 \mathrm{mmol}$ ) was added to a solution of $2(76 \mathrm{mg}, 0.07 \mathrm{mmol})$ in $\mathrm{CH}_{3} \mathrm{OH}(15 \mathrm{~mL})$ at room temperature and the mixture was stirred for $24 \mathrm{~h}$ to give a deep red solution. Upon the addition of diethyl ether, a blackred solid was precipitated and washed with diethyl ether $(3 \times 3 \mathrm{~mL})$ and dried under vacuum $(63 \mathrm{mg}, 72 \%)$. HRMS-ESI $(m / z):[3 a-4 \mathrm{OTf}]^{4+}$ calcd for $\mathrm{C}_{100} \mathrm{H}_{100} \mathrm{O}_{20} \mathrm{~N}_{8} \mathrm{~F}_{12} \mathrm{~S}_{4} \mathrm{Rh}_{4}$, 476.0966; found, 476.0963.

Method C: AgOTf (36 mg, $0.14 \mathrm{mmol})$ was added to a solution of $\left[\mathrm{Cp}^{*}{ }_{2} \mathrm{Rh}_{2}\left(\mu-\eta^{2}-\eta^{2}-\mathrm{C}_{2} \mathrm{O}_{4}\right) \mathrm{Cl}_{2}\right](45 \mathrm{mg}, 0.07 \mathrm{mmol})$ in $\mathrm{CH}_{3} \mathrm{OH}(10 \mathrm{~mL})$ at room temperature and the mixture was stirred for $1 \mathrm{~h}$, followed by filtration to remove insoluble materials. Then trans-4,4'-stilbenediamine (15 mg, $0.07 \mathrm{mmol})$ was added to the filtrate. A solution of 4-formylpyridine (15 mg, $0.14 \mathrm{mmol}$ ) in $7 \mathrm{~mL} \mathrm{CHCl}_{3}$ was then added dropwise to the mixture and stirred for $24 \mathrm{~h}$. The solvent was concentrated to about $3 \mathrm{~mL}$. Diethyl ether was then added, and a black-red solid precipitated, which was washed with diethyl ether $(3 \times 3 \mathrm{~mL})$ and chloroform $(2 \times 3 \mathrm{~mL})$ and dried under vacuum (66 mg, 75\%). HRMS-ESI $(\mathrm{m} / \mathrm{z}):[3 \mathbf{a}-4 \mathrm{OTf}]^{4+}$ calcd for $\mathrm{C}_{100} \mathrm{H}_{100} \mathrm{O}_{20} \mathrm{~N}_{8} \mathrm{~F}_{12} \mathrm{~S}_{4} \mathrm{Rh}_{4}$, 476.0966; found, 476.1010.

\section{Synthesis of $\left[\mathrm{Cp}^{*}{ }_{4} \mathrm{Rh}_{4}\left(\mu-\eta^{2}-\eta^{2}-\right.\right.$ $\left.\left.\mathrm{C}_{2} \mathrm{O}_{4}\right)_{2}(\mathrm{~L} 2)_{2}\right](\mathrm{OTf})_{4}(\mathbf{3 b})$}

Method A: AgOTf (36 mg, $0.14 \mathrm{mmol}$ ) was added to a solution of $\left[\mathrm{Cp}^{*}{ }_{2} \mathrm{Rh}_{2}\left(\mu-\eta^{2}-\eta^{2}-\mathrm{C}_{2} \mathrm{O}_{4}\right) \mathrm{Cl}_{2}\right](45 \mathrm{mg}, 0.07 \mathrm{mmol})$ in $\mathrm{CH}_{3} \mathrm{OH}(15 \mathrm{~mL})$ at room temperature and the mixture was stirred for $1 \mathrm{~h}$, followed by filtration to remove insoluble materials. Then a solution of $\mathbf{L 2}(24 \mathrm{mg}, 0.07 \mathrm{mmol})$ in $7 \mathrm{~mL} \mathrm{CHCl}_{3}$ was added dropwise to the filtrate. The mixture was stirred at room temperature for $24 \mathrm{~h}$ and filtered. The resulting yellow solid was washed with chloroform $(2 \times 3 \mathrm{~mL})$ and dried under vacuum (61 mg, 70\%). ${ }^{1} \mathrm{H}$ NMR (400 MHz, DMSO- $\left.d_{6}, \mathrm{ppm}\right) \delta$ $8.74(\mathrm{~s}, 4 \mathrm{H},-\mathrm{NCH}-), 8.25$ (d, $J=6.0 \mathrm{~Hz}, 8 \mathrm{H}), 7.98$ (d, $J=$ $6.0 \mathrm{~Hz}, 8 \mathrm{H}), 7.87(\mathrm{~d}, J=8.8 \mathrm{~Hz}, 4 \mathrm{H}), 7.13(\mathrm{t}, 4 \mathrm{H}), 7.05(\mathrm{~d}, J=$ $6.8 \mathrm{~Hz}, 4 \mathrm{H}), 1.59(\mathrm{~s}, 60 \mathrm{H}, \mathrm{Cp} *-\mathrm{H})$; HRMS-ESI $(\mathrm{m} / \mathrm{z})$ : 
$[\mathbf{3 b}-4 \mathrm{OTf}]^{4+}$ calcd for $\mathrm{C}_{92} \mathrm{H}_{92} \mathrm{O}_{20} \mathrm{~N}_{8} \mathrm{~F}_{12} \mathrm{~S}_{4} \mathrm{Rh}_{4}, 450.0809$; found, 450.0873 .

Method B: 1,5-Diaminonaphthalene (11 $\mathrm{mg}, 0.07 \mathrm{mmol})$ was added to a solution of $2(76 \mathrm{mg}, 0.07 \mathrm{mmol})$ in $\mathrm{CH}_{3} \mathrm{OH}(20 \mathrm{~mL})$ at room temperature and the mixture was stirred for $24 \mathrm{~h}$ to give a deep red solution. The volume was reduced to $3 \mathrm{~mL}$ in vacuo. Upon addition of diethyl ether, a yellow solid precipitated, which was washed with diethyl ether $(3 \times 5 \mathrm{~mL})$ and dried under vacuum $(61 \mathrm{mg}, 73 \%)$. HRMS-ESI $(\mathrm{m} / \mathrm{z})$ : [3b $-4 \mathrm{OTf}]^{4+}$ calcd for $\mathrm{C}_{92} \mathrm{H}_{92} \mathrm{O}_{20} \mathrm{~N}_{8} \mathrm{~F}_{12} \mathrm{~S}_{4} \mathrm{Rh}_{4}, 450.0809$; found, 450.0807 .

Method C: AgOTf (36 mg, $0.14 \mathrm{mmol})$ was added to a solution of $\left[\mathrm{Cp}^{*}{ }_{2} \mathrm{Rh}_{2}\left(\mu-\eta^{2}-\eta^{2}-\mathrm{C}_{2} \mathrm{O}_{4}\right) \mathrm{Cl}_{2}\right](45 \mathrm{mg}, 0.07 \mathrm{mmol})$ in $\mathrm{CH}_{3} \mathrm{OH}(15 \mathrm{~mL})$ at room temperature and the mixture was stirred for $1 \mathrm{~h}$, followed by filtration to remove insoluble materials. Then, 1,5-diaminonaphthalene $(11 \mathrm{mg}, 0.07 \mathrm{mmol})$ was added to the filtrate. A solution of 4-formylpyridine $(15 \mathrm{mg}$, $0.14 \mathrm{mmol}$ ) in $7 \mathrm{~mL} \mathrm{CHCl}_{3}$ was added dropwise to the mixture and stirred for $24 \mathrm{~h}$. A yellow solid precipitated, which was washed with chloroform $(2 \times 3 \mathrm{~mL})$ and dried under vacuum (60 mg, 72\%). HRMS-ESI $(\mathrm{m} / \mathrm{z})$ : [3b $-4 \mathrm{OTf}]^{4+}$ calcd for $\mathrm{C}_{92} \mathrm{H}_{92} \mathrm{O}_{20} \mathrm{~N}_{8} \mathrm{~F}_{12} \mathrm{~S}_{4} \mathrm{Rh}_{4}$, 450.0809; found, 450.0868.

\section{Acknowledgements}

The authors gratefully acknowledge financial support from the NSFC (Nos. 21722105, 21102004, 21771146), the Scientific Research Foundation for the Returned Overseas Scholars of Shaanxi Province (2017001), the Shaanxi Key Laboratory of Physical-inorganic Chemistry (17JS133), the FM \& EM International Joint Laboratory of Northwest University, and NSF of Anhui Province (1708085MB44).

\section{ORCID ${ }^{\circledR}$ iDs}

Wei-Guo Jia - https://orcid.org/0000-0001-7976-7543

Ying-Feng Han - https://orcid.org/0000-0002-9829-4670

\section{References}

1. Fish, R. H. Coord. Chem. Rev. 1999, 185-186, 569-584. doi:10.1016/S0010-8545(99)00011-9

2. Severin, K. Coord. Chem. Rev. 2003, 245, 3-10. doi:10.1016/S0010-8545(03)00028-6

3. Severin, K. Chem. Commun. 2006, 3859-3867. doi:10.1039/b606632c

4. Boyer, J. L.; Kuhlman, M. L.; Rauchfuss, T. B. Acc. Chem. Res. 2007, 40, 233-242. doi:10.1021/ar050215j

5. Thanasekaran, P.; Lee, C.-C.; Lu, K.-L. Acc. Chem. Res. 2012, 45, 1403-1418. doi:10.1021/ar200243w

6. Cook, T. R.; Vajpayee, V.; Lee, M. H.; Stang, P. J.; Chi, K.-W. Acc. Chem. Res. 2013, 46, 2464-2474. doi:10.1021/ar400010v

7. Han, Y.-F.; Jia, W.-G.; Yu, W.-B.; Jin, G.-X. Chem. Soc. Rev. 2009, 38, 3419-3434. doi:10.1039/b901649j

8. Han, Y.-F.; Jin, G.-X. Chem. Soc. Rev. 2014, 43, 2799-2823. doi:10.1039/C3CS60343A
9. Han, Y.-F.; Jin, G.-X. Acc. Chem. Res. 2014, 47, 3571-3579. doi:10.1021/ar500335a

10. Lu, Y.; Deng, Y.-X.; Lin, Y.-J.; Han, Y.-F.; Weng, L.-H.; Li, Z.-H.; Jin, G.-X. Chemistry 2017, 3, 110-121. doi:10.1016/j.chempr.2017.06.006

11. Mirtschin, S.; Slabon-Turski, A.; Scopelliti, R.; Velders, A. H.; Severin, K. J. Am. Chem. Soc. 2010, 132, 14004-14005. doi:10.1021/ja1063789

12. Conrady, F. M.; Fröhlich, R.; Schulte to Brinke, C.; Pape, T.; Hahn, F. E. J. Am. Chem. Soc. 2011, 133, 11496-11499. doi:10.1021/ja205021p

13. Lee, H.; Elumalai, P.; Singh, N.; Kim, H.; Lee, S. U.; Chi, K.-W. J. Am. Chem. Soc. 2015, 137, 4674-4677. doi:10.1021/jacs.5b02573

14. Zhang, W.-Y.; Lin, Y.-J.; Han, Y.-F.; Jin, G.-X. J. Am. Chem. Soc. 2016, 138, 10700-10707. doi:10.1021/jacs.6b06622

15. Liu, Q.; Zhang, W.-H.; Lang, J.-P. Coord. Chem. Rev. 2017, 350, 248-274. doi:10.1016/j.ccr.2017.06.027

16. Lang, J.-P.; Xu, Q.-F.; Chen, Z.-N.; Abrahams, B. F. J. Am. Chem. Soc. 2003, 125, 12682-12683. doi:10.1021/ja036995d

17. Zhang, W.-H.; Ren, Z.-G.; Lang, J.-P. Chem. Soc. Rev. 2016, 45, 4995-5019. doi:10.1039/C6CS00096G

18. Wang, W.; Wang, Y.-X.; Yang, H.-B. Chem. Soc. Rev. 2016, 45 , 2656-2693. doi:10.1039/C5CS00301F

19. Cotton, F. A.; Lin, C.; Murillo, C. A. Acc. Chem. Res. 2001, 34, 759-771. doi:10.1021/ar010062+

20. Fujita, M.; Tominaga, M.; Hori, A.; Therrien, B. Acc. Chem. Res. 2005, 38, 369-378. doi:10.1021/ar040153h

21. Caulder, D. L.; Raymond, K. N. Acc. Chem. Res. 1999, 32, 975-982. doi:10.1021/ar970224v

22. Saalfrank, R. W.; Maid, H.; Scheurer, A. Angew. Chem., Int. Ed. 2008, 47, 8794-8824. doi:10.1002/anie.200702075

23. Qiu, X.-T.; Yao, R.; Zhou, W.-F.; Liu, M.-D.; Liu, Q.; Song, Y.-L.; Young, D. J.; Zhang, W.-H.; Lang, J.-P. Chem. Commun. 2018, 54, 4168-4171. doi:10.1039/C8CC01950A

24. Zhang, W.-H.; Liu, Q.; Lang, J.-P. Coord. Chem. Rev. 2015, 293-294, 187-210. doi:10.1016/j.ccr.2014.12.010

25. Lang, J.-P.; Xu, Q.-F.; Yuan, R.-X.; Abrahams, B. F. Angew. Chem., Int. Ed. 2004, 43, 4741-4745. doi:10.1002/anie.200460076

26. Liu, D.; Lang, J.-P.; Abrahams, B. F. J. Am. Chem. Soc. 2011, 133, 11042-11045. doi:10.1021/ja203053y

27. Sun, L.-Y.; Sinha, N.; Yan, T.; Wang, Y.-S.; Tan, T. T. Y.; Yu, L.; Han, Y.-F.; Hahn, F. E. Angew. Chem., Int. Ed. 2018, 57, 5161-5165. doi:10.1002/anie.201713240

28. Cook, T. R.; Stang, P. J. Chem. Rev. 2015, 115, 7001-7045. doi:10.1021/cr5005666

29. Zhang, Y.-Y.; Gao, W.-X.; Lin, L.; Jin, G.-X. Coord. Chem. Rev. 2017, 344, 323-344. doi:10.1016/j.ccr.2016.09.010

30. Wu, G.-Y.; Chen, L.-J.; Xu, L.; Zhao, X.-L.; Yang, H.-B. Coord. Chem. Rev. 2018, 369, 39-75. doi:10.1016/j.ccr.2018.05.009

31. Zhang, H.-N.; Gao, W.-X.; Deng, Y.-X.; Lin, Y.-J.; Jin, G.-X. Chem. Commun. 2018, 54, 1559-1562. doi:10.1039/C7CC09448E

32. Han, Y.-F.; Li, H.; Jin, G.-X. Chem. Commun. 2010, 46, 6879-6890. doi:10.1039/c0cc00770f

33. Han, Y.-F.; Lin, Y.-J.; Jia, W.-G.; Jin, G.-X. Organometallics 2008, 27, 4088-4097. doi:10.1021/om800426e

34. Han, Y.-F.; Jia, W.-G.; Lin, Y.-J.; Jin, G.-X. Organometallics 2008, 27, 5002-5008. doi:10.1021/om800490s

35. Han, Y.-F.; Jia, W.-G.; Lin, Y.-J.; Jin, G.-X. Angew. Chem., Int. Ed. 2009, 48, 6234-6238. doi:10.1002/anie.200805949 
36. Vajpayee, V.; Bivaud, S.; Goeb, S.; Croué, V.; Allain, M.; Popp, B. V.; Garci, A.; Therrien, B.; Sallé, M. Organometallics 2014, 33, 1651-1658. doi:10.1021/om401142j

37. Zarra, S.; Wood, D. M.; Roberts, D. A.; Nitschke, J. R. Chem. Soc. Rev. 2015, 44, 419-432. doi:10.1039/C4CS00165F

38. Granzhan, A.; Schouwey, C.; Riis-Johannessen, T.; Scopelliti, R.; Severin, K. J. Am. Chem. Soc. 2011, 133, 7106-7115. doi:10.1021/ja200580x

39. Schouwey, C.; Scopelliti, R.; Severin, K. Chem. - Eur. J. 2013, 19, 6274-6281. doi:10.1002/chem.201300098

40. Liu, X.; Liu, H.; Zhou, W.; Zheng, H.; Yin, X.; Li, Y.; Guo, Y.; Zhu, M.; Ouyang, C.; Zhu, D.; Xia, A. Langmuir 2010, 26, 3179-3185. doi:10.1021/la903838w

41. Min, D.; Cho, B.-Y.; Lee, S. W. Inorg. Chim. Acta 2006, 359, 577-584. doi:10.1016/j.ica.2005.09.041

\section{License and Terms}

This is an Open Access article under the terms of the Creative Commons Attribution License (http://creativecommons.org/licenses/by/4.0). Please note that the reuse, redistribution and reproduction in particular requires that the authors and source are credited.

The license is subject to the Beilstein Journal of Organic Chemistry terms and conditions:

(https://www.beilstein-journals.org/bjoc)

The definitive version of this article is the electronic one which can be found at: $\underline{\text { doi: } 10.3762 / \text { bjoc. } 14.178}$ 